\title{
Una posición con base metaética respecto del aborto y del concepto de dignidad humana ${ }^{(*)}$
}

\author{
A metaethically based position on abortion and the concept of human dignity
}

\author{
Rafael Horacio Molina Castillo(*) \\ Pontificia Universidad Católica del Perú (Lima, Perú)
}

Resumen: Un problema usual en el discurso moral es el riesgo de incurrir en regresiones infinitas. Ello, junto con otras críticas también dirigidas a las disciplinas científicas, motivó la actitud escéptica respecto de la moral aconsejada por varias teorías postmodernas. Tanto la respuesta de la filosofía moral como de la ciencia fue similar: reafirmar la posibilidad de lograr acuerdos de "verdad" o "corrección" mediante la discusión racional, la que implica a su vez un procedimiento reglado para someter teorías a cuestionamientos de la manera más libre posible. En este trabajo el autor pretende destacar algunos elementos del discurso racional que son de uso característico en el discurso práctico, para luego aplicarlo a una discusión sobre el aborto. El propósito central de esta investigación es aportar al análisis de la justificabilidad de la dignidad en el feto. Dicha discusión implica primero la identificación de una teoría de la dignidad que satisfaga apropiadamente la exigencia de universalidad de todo discurso racional, para luego aplicarla a algunos de los argumentos usuales en el debate del aborto.

Palabras Clave: Teoría del discurso - Aborto - Dignidad - Teoría de las capacidades Postmodernismo - Escepticismo - Racionalidad - Kant - Alexy

\begin{abstract}
A common problem in moral discourse is the risk of incurring in infinite regressions. This, together with other criticisms also directed at scientific disciplines, motivated the sceptical attitude towards morality advised by several postmodern theories. The response of both moral philosophy and science was similar: to reaffirm the possibility of reaching agreements of "truth" or "correction" through rational discussion, which in turn implies a regulated procedure to submit theories to questioning in the freest possible way. In this paper the author intends to delineate some elements of rational discourse that are characteristically used in practical discourse, and then apply them to a discussion of abortion. The central purpose of this research consists in contributing to the analysis of the justifiability of the idea that the fetus can have dignity. This discussion implies first identifying a theory of dignity that appropriately satisfies the demand for universality of all rational discourse, and then applying it to some of the usual arguments in the abortion debate.
\end{abstract}

Key words: Discourse theory - Abortion - Dignity - Theory of capacities - Postmodernism - Skepticism - Rationality - Kant - Alexy

(*) Nota del Editor: Este artículo fue recibido el 15 de setiembre de 2020 y su publicación fue aprobada el 12 de noviembre de 2020.

${ }^{* *}$ Bachiller en Derecho por la Pontificia Universidad Católica del Perú. Candidato a LL.M. en Principios del Derecho Alemán con especialidad en Filosofía del Derecho en la Ludwig-Maximillians-Universität München. Miembro extraordinario de IUS ET VERITAS y ex Director de Investigación durante el semestre 2015-1. ORCID: https://orcid.org/0000-0002-9780-3023. Correo electrónico: rafael. molina@pucp.edu.pe 


\section{Introducción}

La discusión sobre la justicia del aborto enciende emociones morales altamente antagónicas y violentas: la supuesta opresión de la mujer y el supuesto sacrificio de una persona inocente. Se trata, no obstante, de una pregunta moral y jurídica que suele sostenerse sobre la base de la apelación al concepto de dignidad, tanto del feto como de la madre. El propósito central de este trabajo es analizar con mayor detenimiento la justificabilidad de la dignidad de un feto.

La primera sección de la investigación establece una base metaética sobre la que se puede llevar a cabo la discusión. Una pregunta previa al análisis de la justificabilidad de un juicio moral es responder si siquiera es posible justificar racionalmente premisas morales. No puedo dar una respuesta original a esta pregunta en este trabajo, por lo que esta sección de la investigación se limita a constatar algunas teorías que pueden responder a esta interrogante.

La segunda sección trata de encontrar un concepto de dignidad y sus justificaciones. Aquí analizo críticamente la tradicional teoría de la autonomía y la confronto con la teoría de las capacidades de Nussbaum, que tampoco está libre de cuestionamientos. El resultado es una propuesta del criterio de titularidad de la dignidad basado en una justificación "existencialista" propuesta por Alexy. No obstante, una fundamentación completa de esta propuesta no puede realizarse en este trabajo.

La tercera sección analiza la cuestión de si el feto puede ser considerado un ser vivo con dignidad, así como las consecuencias de prohibir el aborto respecto de la dignidad de la mujer. Estas cuestiones son altamente complejas, por los que su análisis solo puede llevar a un resultado prima facie, en consideración de la teoría propuesta. No obstante, varias posturas son resueltas y varias preguntas son excluidas; varias, no obstante, no pueden evitar quedar abiertas.

Este ensayo no analiza los casos de aborto en los que la vida de la madre está en peligro o que son resultado de la violencia sexual. Asumo que ya existe un consenso moral ampliamente difundido en relación con estos casos (Nussbaum, 2011, p. 7). Sin embargo, mi análisis provee argumentos aplicables a estos casos también.

\section{Prefacio metaético}

El propósito de esta sección es hacer explícitas algunas premisas metaéticas que utilizaré después para analizar la situación de la dignidad en el caso del aborto. Considero que hay dos problemas que toda argumentación moral debe superar: 1) debe identificar el riesgo de la regresión infinita y proveer un cierre analítico a su argumentación; 2) debe también evitar caer en una metafísica ${ }^{(1)}$ inconmensurable con la racionalidad. Precisamente pretendo superar estos problemas mediante la exposición de mis presupuestos en esta sección.

En la medida que el centro del artículo constituye la discusión en torno al aborto, no puedo detenerme a someter a prueba y cuestionar detenidamente las premisas que expongo en esta sección. Debe quedar presente que estas premisas no están libres de críticas, las cuales algunas serán señaladas.

Debe también tenerse presente que cuando hablo aquí de moral me refiero a la moral crítica, definida como los principios morales utilizados para cuestionar instituciones públicas, opuesta a la moral positiva, que identifica los valores fácticamente vigentes en un grupo social (Hart, 1963, p. 20).

\subsection{Un concepto de verdad}

La tesis principal del posmodernismo cuestiona la posibilidad de acceder a la verdad; de esta premisa suele derivarse la idea de que no pueden establecerse criterios para identificar mejores razones que otras. En consecuencia, las disciplinas científicas y académicas serían inútiles. Particularmente, en la moral, ello conlleva la idea de que no pueden identificarse mejores argumentos morales que otros. A esto se le ha llamado "escepticismo ético" (Nino, 1989, p. 54).

Existe un patrón identificable en el modo en que distintas disciplinas han respondido a la premisa escéptica: la verdad en el "resultado" ha sido reemplazada por la "verdad procedimental". Un ejemplo se presenta en las ciencias naturales; este ejemplo sirve de comparación ilustrativa precisamente porque estas disciplinas gozan

(1) Debe entenderse que en este artículo pretendo evitar aquello que autores como Alexy (2004, p. 22) han denominado "metafísica enfática", que implica aquello que consta de las 5 siguientes características: 1 ) no puede ser detectado mediante la experiencia; 2 ) implica explicaciones que pretenden abarcarlo todo; 3) es invariable, 4) tiene contenido normativo, 5) tiene una dimensión espiritual o religiosa. 
de mayor credibilidad. En ellas no se discute que sus teorías no representan una verdad absoluta, sino un "acercamiento" a ella (o un alejamiento de la falsedad, desde el punto de vista de Popper). El acercamiento a la verdad -que es, a su vez, la razón por la que confiamos en la ciencia- se mide exclusivamente en relación a la existencia de un procedimiento riguroso de producción de conocimiento, que impone todos los esfuerzos posibles para excluir teorías falsas. En consecuencia, confiamos en la ciencia no porque sea verdadera, sino porque su método es confiable (Chalmers, 2013, p. 211). Entonces, la respuesta de las ciencias naturales a la actitud escéptica ha sido establecer una "verdad procedimental".

Una respuesta similar es propuesta por algunos autores en la filosofía moral y en el Derecho; algunos de los más importantes son Karl-Otto Apel ${ }^{(2)}$, Jürgen Habermas ${ }^{(3)}$ y Robert Alexy ${ }^{(4)}$ que proponen una verdad formada mediante procedimientos discursivos. El primer paso de estas explicaciones consiste en un planteamiento del concepto de verdad.

El concepto de "verdad" clásico es la verdad como correspondencia. De acuerdo a este, un enunciado es verdadero si los hechos que describe existen en el mundo (Alexy, 2019, pp. 135-136).

Hay varios problemas con este concepto de realidad, pero aquí bastará exponer dos. En primer lugar, no puede identificar satisfactoriamente qué es aquello que debería considerarse como un "hecho". Como ha demostrado Popper, la decisión de aislar parcelas de la realidad para imputarles la calificación de "hecho" pretende justificarse sobre la asunción de teorías de la realidad, que se asumen como ciertas. En realidad, esas teorías no pueden ser calificadas como verdaderas, ya que han sido construidas de manera inductiva, es decir, creando reglas generales a partir de observaciones particulares; como se sabe, no puede asegurarse la certeza absoluta de teorías creadas de manera inductiva, pues siempre resta la probabilidad de que un evento que escape a la regla ocurra en el universo. Entonces, los hechos, cuya identificación depende de un sistema de presuposiciones, jamás pueden ser probados como absolutamente ciertos, ya que ninguna de sus presuposiciones puede ser calificada así (Popper, 1973, p. 73). En segundo lugar, como han sostenido los antirrealistas globales, es imposible tener contacto con aquella realidad "objetiva" que existe allá afuera, con independencia de nosotros, dado que nuestros sentidos limitan la parcela de la realidad a la que podemos tener acceso; estamos irremediablemente sesgados, pues nada excluye la posibilidad de que la realidad se extienda más allá de lo que nuestros sentidos nos permiten percibir (Chalmers, 2013, pp. 210-211).

En oposición a esta teoría, Habermas postula la teoría del consenso (Habermas, 1973). Aquí no puedo analizar cada detalle de esta teoría, pero será suficiente sentar algunos elementos necesarios para nuestra investigación. Esta teoría acepta que los humanos no podemos aprehender directamente la realidad, sino que nuestra percepción está limitada por nuestros sentidos; para nosotros, la realidad es siempre una realidad interpretada (Freundlieb, 1975, p. 100). Esta interpretación que llamamos "realidad" es una construcción del lenguaje. El sistema de lenguaje constituye un sistema de conceptos que construimos discursivamente y que pretenden reflejar dicha realidad. Hasta aquí, se aceptan las críticas postmodernistas.

El concepto de verdad de esta teoría presupone la teoría de los "actos del habla" desarrollada por John Langshaw Austin, por lo que es preciso comprender primero este concepto. De acuerdo a esta teoría, la comunicación no solo se utiliza para construir significados o describir el mundo (algo que Austin criticó al Wittgenstein del Tractatus LogicoPhilosophicus), sino también para realizar acciones o "actos del habla". Por ejemplo, "dar un consejo", "amenazar" o "prometer" son acciones que se realizan al hablar, y su calificación como tal trasciende el mero significado de aquello que se dice. ¿Cómo sabemos qué acto del habla se realiza y como distinguimos uno de otro? Un elemento importante de esta teoría implica la proposición de reglas, fácticamente existentes, que no siempre son del todo claras, que determinan cuándo se realiza un acto del habla (Austin, 1962, pp. 3-6).

En la teoría de Habermas, la verdad se entiende en el marco de la comunicación: algunos actos del habla ${ }^{(5)}$-como por ejemplo

(2) Véase Karl-Otto Apel (1973). Das A priori der Kommunikationsgemeinschaft und die Grundlagen der Ethik. En Transformation der Philosophie (pp. 358-435). Suhrkamp.

(3) Véase Habermas, J. (1996). Ética del discurso - notas sobre un programa de fundamentación. En Conciencia moral y accion comunicativa (edición original) (pp. 57-134). Ediciones Península.

Diskursethik - Notizen zu einem Begründungsprogramm. En Moralbewußtsein und kommunikatives Handeln (pp. 53-126). Suhrkamp.

(4) Véase Alexy, (2019).

(5) Habermas denomina a este tipo como "actos constativos"; serían los únicos pasibles de ser calificados como verdaderos o falsos. 
las "afirmaciones"-, implican la idea de que un enunciado es cierto respecto de todos los demás hablantes, de manera universal. Por ejemplo, cuando afirmo "el sol emite luz", sugiero a la vez que este hecho es cierto respecto de todos los interlocutores posibles e imaginables (es decir, respecto de todos los humanos). Esta pretensión de universalidad adquiere fuerza y forma consensos cuando ella es válida intersubjetivamente (es decir, cuando su pretensión es aceptada y compartida por otros) (Habermas, 1973, p. 311).

La mera validez intersubjetiva de esta pretensión de universalidad no basta para calificar a algo como verdadero. Es posible y frecuente que la opinión de una mayoría fáctica no resista el más mínimo análisis racional. En este punto se perfila el concepto de verdad habermaseano: la verdad es un consenso justificado; un enunciado es cierto cuando es racionalmente aceptable (Habermas, 1998, p. 191). El reconocimiento de una idea como verdadera -su justificación- depende de la fuerza de convencimiento de los argumentos que se den por ella; en otras palabras, la verdad está dada por un consenso en torno a argumentos convincentes (Habermas, 1982, p. 38). Aquí se impone la pregunta: ¿cuándo es un argumento racional?

\subsection{Racionalidad y pretensión de universalidad}

En la medida que esta investigación está relacionada a una cuestión práctica -la dignidad en el aborto-, me limito aquí a la racionalidad en el discurso práctico o moral. Cabe destacar que en escritos más recientes Habermas argumenta que, aunque no puede hablarse de "verdad" moral, porque la "verdad" hace referencia al mundo físico, sí puede hablarse de corrección moral, que tiene en común con la verdad "física" criterios de racionalidad y objetividad (Habermas, 1998, p.189).

Hay varios criterios que determinan la racionalidad $-\mathrm{u}$ objetividad-. Tal vez el más importante sea la universalidad. En líneas anteriores, he mencionado que hay un tipo de actos del habla que involucran necesariamente una pretensión de validez universal. La única forma de comprobar esta validez es comprobar su pretensión, es decir, constar su conformidad con todos los destinatarios que pretende: todos los humanos que hayan existido y existirán; entonces, para que un argumento valga como fundamento de una "verdad", el enunciado debe poder resistir todos los cuestionamientos que, en teoría, todo miembro de la raza humana podría increparle; debe ser reconocido como el argumento más convincente en una "situación ideal de discusión". Aquí se resalta el vínculo de la "verdad" con la argumentación y el discurso. Una situación ideal de discusión permite el máximo cuestionamiento imaginable de una idea: es un contexto ideal en el que todos los seres humanos pueden entrar a debatir y cuestionar una idea de manera absolutamente libre, al punto de extender el debate sin límite, hasta el momento en que todas las dudas hayan sido resueltas (Habermas, 1973, p. 255).

Naturalmente, no es posible recrear una situación ideal de discusión. Es por ello que la absoluta verdad tampoco puede ser alcanzada. No obstante, es posible acercarnos a la situación ideal, y una idea puede tener mayor carácter de verdad en la medida que haya sido discutida en un contexto que se acerque a dicha situación ideal. Incluso en el supuesto en que una idea pudiera ser sometida a una discusión ideal completa, ella tampoco adquiriría un valor de verdad inamovible, dado que nuevos argumentos pueden surgir con el paso del tiempo y el cambio de valores y tecnologías (Keuth, 1979, pp. 378-379). En ese sentido, usando la terminología de Kant, la verdad es una idea regulativa, en el sentido de que no representa algo existente en el mundo, sino un objetivo al que debe aspirarse ${ }^{(6)}$ (Höffe, 2014, p. 129).

Aquí uno podría refutar que en los juicios o normas morales no hay tales afirmaciones de universalidad. Recordemos que cuando una persona realiza el acto del habla de, por ejemplo, "afirmación" (por ejemplo, "aquella manzana es roja"), asume inevitablemente que esa descripción representa la misma "realidad" para todo observador posible (en el ejemplo, el hablante asumiría que la manzana es roja respecto de todo observador). En respuesta -siguiendo a Hare-, se debe decir que lo mismo ocurre cuando se hacen

(6) Es interesante notar la similitud de esta teoría de verdad con el falsacionismo de Popper, aplicable a la ciencia. Partiendo de una teoría de la verdad como correspondencia, Popper acepta que la ciencia no puede aspirar a establecer verdades. No obstante, el progreso científico se mide mediante la aceptación de teorías que sobreviven intentos de ser probadas como falsas. Si bien no podemos aspirar a la verdad, podemos aspirar a la mejor teoría posible. El consenso científico se forma en torno a dichas teorías (Chalmers, 2013, p. 64). Esta teoría se asemeja a la verdad como consenso racional en el hecho de identificar "las mejores verdades posibles" de acuerdo a su fuerza de convencimiento, la cual es calculada por su aptitud para tolerar contraargumentos. De hecho, Alexy considera que las reglas del discurso racional implican, de por sí, una exposición a intentos de falsacionismo (Alexy, 2019, p. 175). 
afirmaciones normativas: cuando un hablante afirma que algo es, por ejemplo, bueno, pretende afirmar que existe un concepto de lo Bueno que califica a ese algo, en esa circunstancia específica, como bueno a los ojos de todo observador (Hare, 1963, pp. 10-11, 30).

Frente a esto, uno podría replicar que esta premisa escondida con pretensión de universalidad no representa objetividad alguna, sino más bien decisiones, sentimientos, gustos, arbitrariedades del hablante. A esta refutación se le responde de dos maneras:

(i) Estudios psicológicos han descubierto que la percepción que las personas tenemos respecto de los valores morales se asemeja a la percepción que tenemos respecto de entidades físicas: creemos inevitablemente que los valores tienen ciertas características y que estas son independientes de la voluntad de uno mismo; esta percepción se aprende y puede variar mediante el aprendizaje (Habermas, 1998, p. 184).

(ii) Existen actos del habla por medio de los cuales las personas expresamos decisiones y sentimientos, pero estos se diferencian de los actos del habla en que, como las afirmaciones, irrenunciablemente expresamos ideas con pretensión de validez universal.

La racionalidad en el discurso práctico está determinada por más criterios. No obstante, se podría decir que la pretensión de universalidad es una puerta de entrada a ellos, dado que a partir de ella varias teorías han pretendido deducir los otros aspectos. Este desarrollo de criterios suele ser agrupado en las denominadas Teorías del Discurso. Ejemplos de ellas son las propuestas por Habermas ${ }^{(7)}$, Karl-Otto Apel(8), Neil MacCormick ${ }^{(9)}$, entre otros. En este apartado me quiero referir principalmente a la de Robert Alexy ${ }^{(10)}$.

\subsection{Teoría del discurso y racionalidad universal}

Hasta ahora tenemos que el criterio de verdad (o corrección) en el discurso práctico está dado por la aceptabilidad racional de argumentos, y que la determinación de "verdades" se resuelve mediante la discusión racional. Las reglas elaboradas por la teoría del discurso pretenden aprehender aquello que hace racional a una discusión. En este segmento no pretendo exponer todas las reglas del discurso en la teoría de Robert Alexy, pues ello escaparía del centro de esta investigación; resaltaré no obstante algunos conceptos y algunas reglas que servirán para 1) exponer una posible solución a los problemas del discurso moral que expliqué al inicio de este subcapítulo y 2) más adelante serán relevantes en el debate mismo del concepto de dignidad.

Una forma ilustrativa de exponer este tema es comenzar por la justificación de la teoría del discurso como un todo: la justificación de la teoría propone un argumento que afirma su universalidad o validez intercultural y a la vez pretende evitar los problemas de regresión infinita y justificaciones metafísicas; a la vez expone el modo en que se deducen las reglas del discurso racional de la idea misma de universalidad.

Hay bastantes formas de justificar la teoría del discurso. La forma que Alexy utiliza se caracteriza por el uso de un "argumento trascendental-pragmático", que recoge su denominación de Kant (Alexy, 2019, p. 231). No hay una definición unívoca de "argumento trascendental", pero para Alexy se trata de argumentos que, cuando menos, tienen las dos siguientes premisas:

- Premisa 1: Identifica el punto de partida del argumento, que consiste en señalar entidades como percepciones, ideas o actos del lenguaje, y afirma que esta entidad es necesaria de algún modo.

- Premisa 2: Argumenta que algunas asunciones o reglas son necesarias para que la entidad señalada en la Premisa 1 sea posible.

- Conclusión: Entonces, la categoría o reglas señaladas en la Premisa 2 son también necesarias (Alexy, 2016, pp. 133134) (Alexy, 2004, pp. 19-20).

El argumento trascendental de Alexy es el siguiente (el orden de las premisas está invertido) (Alexy, 2016, p. 134) (Alexy, 2019, p. $165 ;$ p. 418).

Premisa 2: La realización de los actos del habla consistentes en afirmaciones y justificaciones implican inevitablemente la presuposición de las siguientes asunciones:

(i) Quien afirma algo, cree irremediablemente que aquello que afirma es universalmente cierto: Esta idea ya ha sido explicada en la

(7) Véase pie de página 4.

(8) Véase pie de página 3.

(9) Véase Legal Reasoning and Legal Theory (1978).

(10) Véase Alexy, (2019). 
sección anterior cuando me referí a la teoría de Habermas. Aquí bastará recordar que el acto del habla de "afirmar" implica necesariamente la proposición del carácter de "verdad con validez universal" de las ideas que se afirman.

(ii) El que afirma, cree en esa certeza o "verdad" basándose en razones.

(iii) Los interlocutores de la persona que afirma algo tienen la expectativa de que, en principio, el que afirma podría exponer sus razones y discutir sobre ellas: En los hechos, es posible que el afirmante no desee o no pueda exponer razones; no obstante, la suposición que se propone como necesaria es que siempre que alguien afirma algo, los demás creen necesariamente que el afirmante (i) se basa en razones y que (ii) podría -en principio- exponerlas y discutirlas.

Este punto expone el salto del campo individual al argumentativo-intersubjetivo. También exige ocuparnos en adelante del acto del habla de "justificar".

Este punto también justifica una idea clave de la teoría del discurso de Alexy: que toda premisa moral es discutible, argumentable y justificable; ello no significa que todas las premisas del sistema moral puedan ser justificadas al mismo tiempo; solo significa que (i) siempre pueden darse argumentos por y en contra de premisas, y que (ii) la elección de mejores premisas es siempre posible en función a los argumentos que se den por ella(11) (Alexy, 2019, p. 76).

(iv) Quien realiza el acto del habla de "justificar" una "afirmación" asume necesariamente lo siguiente:

- Igualdad en el discurso: Que las razones en las que el hablante basa la verdad de su información son buenas razones para todos, y debe serlo también para su interlocutor. Su interlocutor solo será convencido por buenas razones, y el hablante asume que sus razones lo son respecto de él.

- Libertad de coerción: Que las razones son ciertas y convencen sin la necesidad de ejercer coerción en el interlocutor.

- Universalidad: Que las razones son universales en la medida que se oponen por su propio peso a las refutaciones que cualquier otra persona tendría.

Lo que aquí Alexy pretende es hacer explícito el contenido implícito de los actos del habla consistentes en "afirmar" y "justificar". Entonces, siempre que en su teoría se mencione esos conceptos, se debe entender que están definidos por la asunción de las suposiciones que he mencionado.

Premisa 1: Dar "justificaciones" y "afirmaciones" en el sentido descrito es imprescindible para formar parte de la "forma de vida más general" (Alexy, 2004, p. 21) (Alexy, 2016, pp. 139-140) (Alexy, 2019, p. 418).

El concepto de "forma de vida" es el utilizado por Wittgenstein(12) en su teoría. Expresado de manera muy general, por "forma de vida" debe entenderse al sistema de reglas y convicciones formadas por el lenguaje en un determinado grupo, y que forman su percepción del mundo. Las "formas de vida" son diferentes entre culturas y sociedades.

El concepto de "forma de vida más general" implica el reconocimiento de que (i) si bien hay diferentes formas de vida, (ii) todas tienen necesariamente premisas con pretensión de universalidad que se evidencian mediante los presupuestos inevitables que he expuesto en la premisa anterior; (iii) todas esas premisas con pretensión de universalidad se basan necesariamente razones, que a su vez se basan en otras razones, así sucesivamente hasta llegar a razones con las que miembros de distintas formas de vida podrían estar de acuerdo; sobre este nivel de acuerdo general necesario es posible la resolución argumentativa de todas las premisas que se deriven y con las que se construye el sistema. En consecuencia, un discurso entre distintas formas de vida (culturas) es en principio posible y no hay inconmensurabilidad insalvable entre ellas.

Se forma parte de la "forma de vida más general" cada vez que se hacen afirmaciones y justificaciones en el sentido expuesto en la premisa anterior. En esa

(11) Véase aquí con Popper, también citado por Alexy, en lo que él llama "el mito del sistema teórico": "Admito que siempre somos prisioneros atrapados en el sistema de nuestras teorías, de nuestras expectativas, de nuestras experiencias pasadas, de nuestro lenguaje. Pero (...) si intentamos, podemos escapar del sistema en cualquier momento. Pero es necesario admitir que nos encontraremos nuevamente en un sistema teórico, pero será uno más grande y espacioso". Popper, Normal Science and its Dangers, en: Criticism and the Growth of Knowledge.

(12) Véase Alexy, (2019, p. 74). 
línea, es inevitable asumir las reglas descritas, salvo que se viva en aislamiento completo de otros seres humanos. La vida en sociedad implica casi insalvablemente la asunción de esas reglas (Alexy, 2016, p. 140). Aquí yace el punto fuerte de la Premisa 1.

De las reglas (o asunciones necesarias) explicitadas en la Premisa 2 se deducen muchas reglas de la racionalidad u objetividad del discurso práctico. Por ejemplo, de la asunción 4) se sigue que los interlocutores no pueden estar sujetos a coerción (Libertad de coerción), deben tener igual participación en el discurso (Igualdad en el discurso) y que las consecuencias de los argumentos morales deben ser aceptables por todos los interlocutores (Universalidad). Estas reglas constituyen un mínimo necesario de toda argumentación y juicio moral, y sirven para identificar y excluir argumentos inaceptables.

Aquí me quiero detener para hacer explícitas dos consecuencias de esta exposición: Si se acepta la argumentación de Alexy, ella representa una solución a los objetivos que me plantee al inicio de esta sección: proveer una justificación para reglas morales que 1) no incurre en una regresión infinita, y que 2) no se basa en metafísica para justificar su carácter universal. La premisa de cierre no-metafísica de esta argumentación implica la aceptación de los presupuestos explicados en la Premisa 2, y que constituyen presuposiciones inevitables de la comunicación humana.

En este punto puede cuestionarse que, si bien las reglas existen, no todas las personas realmente se comportan de acuerdo a ellas. Muchísimas personas forman parte de discusiones y únicamente fingen objetividad con el propósito de manipular y conseguir fines egoístas. También podría cuestionarse que Alexy incurre en una falacia naturalista, al deducir de un hecho (el comportamiento humano) el carácter normativo de las reglas del discurso.

Alexy responde a estas críticas con un argumento que él llama "existencialista", porque implica una decisión sobre quién somos. Las reglas del discurso tienen vigencia respecto de las personas que tienen un auténtico interés en la verdad y la justicia. En la medida que descubrir la verdad sea el objetivo, las reglas del discurso deberán ser cumplidas. Tener ese interés es equivalente a aceptar y llevar a la realidad el potencial discursivo de las personas. Es posible utilizar este interés como justificación, debido a que este interés no es como cualquier otro: de hecho, una mayoría sustancial de personas tienen en todas las sociedades humanas un interés en la "verdad", al punto de obligar fácticamente a los dictadores e injustos a fingir que dicen verdades (Alexy, 2004, p. 21).

\subsection{Algunas precisiones y reglas del discurso}

De estas presunciones inevitables de la comunicación humana se derivan varias reglas de la racionalidad del discurso práctico. Aquí resalto solo algunas de particular importancia para este trabajo.

El principio que cae por su propio peso es el de la universalidad en el discurso práctico. Tras un análisis exhaustivo de varias interpretaciones del mismo, incluyendo el de Habermas, Alexy concluye que la universalidad implica dos reglas: (i) que el hablante considere aceptable las consecuencias de su enunciado normativo, para el caso en que ellas lo afectaran a él ${ }^{(13)}$, (ii) que las consecuencias del enunciado normativo sean aceptables por todos (Alexy, 2019, pp. 251-252).

Un segundo elemento de la racionalidad de la discusión moral implica dilucidar sobre qué se discute. Naturalmente, esa discusión implica una reflexión sobre enunciados normativos (enunciados valorativos). Pero, ¿de dónde surgen los valores? Su justificación no puede ser una basada únicamente en una sucesión de premisas. Ya hemos visto que ello deriva en una regresión infinita.

La postura de Habermas (1973, p. 251), que es compartida por Alexy (2019, p. 174, pp. 234-254), es que los valores y reglas morales se reconducen a una interpretación de las necesidades e intereses de las personas, y de su modo de satisfacerlas. Esta interpretación (y la discusión misma) parte de premisas históricas y culturales preexistentes, y está sujeta a su variación.

Una postura alternativa es la que tiene Nino (1989). Para exponerla, el autor se apoya en una interpretación del equilibrio reflexivo que Rawls expone en $A$ Theory of Justice (1971). Según él, el objeto de la filosofía moral es ordenar nuestros juicios morales de manera sistemática y coherente (Rawls, 1971, pp. 46-47). En tal sistema habría dos elementos básicos: (i) convicciones intuitivas de justicia y (ii) principios morales, que son construcciones racionales que emanan de

(13) Esta regla es análoga al punto de vista requerido por el equilibrio reflexivo de John Rawls en "A Theory of Justice". 
dichas convicciones (Rawls, 1971, pp. 19-20). La tarea de la filosofía moral consistiría en encontrar un contrapeso entre estos dos elementos, eliminando los principios que no pueden reflejar nuestras convicciones más profundas sobre la justicia, y también eliminando las convicciones que no pueden ser justificadas por nuestros principios más fuertes (Rawls, 1971, p. 21, pp. 48-51), lo que puede hacerse mediante la discusión. Nino complementa esta teoría al sugerir que la elección entre los principios morales y las convicciones deben ocurrir en el marco de una discusión racional, que involucre reglas que aseguren su racionalidad, y estas reglas constituirían el tercer elemento (Nino, 1989, pp. 105-107).

Lo interesante del enfoque de Rawls y de Nino es que identifican a las convicciones intuitivas de justicia como un criterio del discurso moral. Estas intuiciones sin duda tienen una dimensión emocional, pues, a veces, pueden determinarse al identificar que "hay respuestas que sentimos deben ser respondidas de algún modo. Por ejemplo, estamos seguros que la intolerancia religiosa y la discriminación racial son injustas" (Rawls, 1971, p. 19). Esta posición coincide con la tesis defendida por el internalismo ético, según la cual las convicciones morales de hecho están acompañadas por emociones y una fuerza motivadora del comportamiento (Hume, 1740, parte 1, Secc. 1, párr. 8).

En comparación a la premisa aceptada por Habermas y Alexy, el reconocimiento de este elemento representa una ventaja, porque da cuenta de este rasgo innegable de la moralidad. Por otro lado, reducir los elementos mínimos del discurso moral a los intereses y necesidades de las personas no es compatible con planteamientos morales que en el pasado y en el presente han reconocido como justos los intereses y necesidades de sujetos que no pueden formar parte del discurso; un ejemplo de ello es la creciente valoración de los derechos de los animales. Tiene además una ventaja comparativa en el discurso racional: es un instrumento para criticar argumentos morales que propongan la existencia de convicciones intuitivas de justicia que, en un contexto histórico y cultural dado, constituyan obvios absurdos emocionales, como por ejemplo la del reconocimiento de un derecho a la vida de las plantas.

Al reconocimiento de las convicciones intuitivas puede cuestionársele que su aceptación rompería con la racionalidad del discurso práctico, pues permitiría la aceptación de premisas morales basadas únicamente en emociones, sin la necesidad de dar argumentos. Pero, como vimos, Nino ha precisado que la elección de la mejor premisa moral debe decidirse en el marco de una discusión racional. De este modo, el concepto de las convicciones intuitivas no serviría para elegir mejores argumentos morales, sino para identificar la validez de los argumentos introducidos al discurso práctico. De tener éxito en el marco de una discusión racional como ha sido expuesta hasta aquí, la mera apelación a una convicción intuitiva no basta, sino que debe basarse en razones.
Un análisis más exhaustivo de las teorías del discurso excedería los propósitos de este artículo, por lo que esta sección debe cerrarse aquí. Lo importante a rescatar, a efectos de aplicarlo a la discusión que sigue, es que las aserciones morales tienen una pretensión de validez universal, que equivale a una pretensión de "verdad", tal cual lo hacen los enunciados descriptivos. $Y$ así como en los enunciados descriptivos, la identificación de esa "verdad" (o, dicho con mayor propiedad, la "corrección") moral ocurre mediante la presentación de argumentos; los argumentos más sólidos y convincentes representan nuestra mejor versión de la verdad. La solidez y el convencimiento de dichos argumentos solo puede identificarse al someterlos a un cuestionamiento máximo; el cuestionamiento ideal ocurriría en la situación ideal de discusión, que es aquella en que todos los participantes del discurso tendrían plena libertad de crítica. Como ello no existe, la mejor forma de acercarnos a la "verdad" es recrear lo mejor posible las condiciones de dicha situación ideal. Ese es precisamente el rol de las reglas del discurso racional.

Hasta ahora hemos identificado dos normas: el principio de universalidad (en sus dos manifestaciones) y la descripción de los elementos que forman parte del debate moral. Alexy ha elaborado un catálogo exhaustivo de reglas adicionales (Alexy, 2019), y Nino ha desarrollado algunas otras (Nino, 1989). Estas reglas son derivaciones de la pretensión de universalidad y la necesidad de promover la presentación de cuestionamientos con la mayor libertad posible. A continuación, menciono algunas de ellas, que son relevantes a en este ensayo:

a) Los principios morales deben ser libremente aceptados: Esto excluye los argumentos que justifican su obediencia por miedo a las amenazas o que se basan en la mera observancia dogmática de las autoridades (como un dios) (Alexy, 2019, p. 239) (Nino, 1989, p. 109) : Este principio se deriva de la necesidad de permitir la crítica libre, con el propósito de posibilitar la presentación de cualquier duda o cuestionamiento.

b) Publicidad de los principios: Los principios 
deben ser públicos para que todos los participantes puedan conocerlos y discutirlos (Alexy, 2019, p. 252) (Nino, 1989, p. 110).

c) Demostrabilidad fáctica: Las características y circunstancias en las que se basan los principios deben ser, en la medida de lo posible, comprobables empíricamente, para que cada participante tenga la oportunidad de cuestionar dicha comprobación (Nino, 1989, p. 110). Esta regla se deriva también del propósito de promover la libre crítica, dado que es imposible demostrar la falsedad de aquello que no se puede probar.

d) Ningún participante del discurso puede contradecirse: La exigencia de coherencia lógica es una condición que se deriva de la pretensión de universalidad: reglas y premisas contradictorias no pueden valer universalmente, dado que no pueden aplicarse ambas al mismo tiempo para juzgar un mismo caso concreto; solo es posible la vigencia de una o de otra. Una regla lógica que vale la pena mencionar en nuestra discusión es la "Ley de Hume" (que, para efectos prácticos, se le denominará aquí como falacia naturalista) ${ }^{(14)}$ : es absolutamente imposible derivar un enunciado normativo de un enunciado descriptivo (Hume, 1740, secc. 1, últ. párr.).

\section{La Dignidad Humana}

La discusión requiere un análisis de algunos planteamientos importantes de la dignidad. Como veremos más adelante, la cuestión de si el aborto viola la dignidad humana conduce a un conflicto de dignidad contra dignidad. Por eso debemos examinar también el contenido de este principio/derecho.

La pregunta sobre la dignidad puede entenderse de dos maneras: 1) ¿qué significa "dignidad" y quién es titular de ella? 2) ¿a qué tiene derecho un titular de la dignidad? Ambas preguntas se analizan a continuación.

\subsection{Titularidad: ¿Cuándo alguien o algo posee "dignidad"?} Históricamente, podemos encontrar, según Hufen, tres categorías amplias de enfoques de la dignidad: i) las teorías de la dote, "que suponen que una cierta cualidad no disponible se da, de hecho predeterminada, al hombre desde el exterior [Dios]" ii) las teorías del logro, que más tarde fueron sustituidas por el enfoque de la autonomía humana. iii) las teorías de la comunicación, que hacen hincapié en la solidaridad y la socialidad entre los seres humanos (y otros seres vivos) (Hufen, 2016, pp. 133-134).

\subsubsection{Teorías de la dote}

Las teorías de la dote no requieren una discusión más profunda aquí. Según su premisa principal, la dignidad proviene de una autoridad no demostrable, y sería moldeada por ella. En consideración de las premisas expuestas en el capítulo anterior, tales ideas no pueden ser consideradas argumentos morales válidos. Esto puede explicarse por dos razones: (i) Tales ideas violan la regla discursiva formal (antes mencionada) de la demostrabilidad de los hechos y la regla de que los principios morales deben ser libremente aceptados (y por lo tanto no pueden emanar simplemente de la autoridad). (ii) Si quisiéramos adoptar la teoría de la dote, tendríamos que renunciar a los principios morales solidos del secularismo del estado y el tratamiento igualitario de las religiones (pluralismo de las religiones) (Hufen, 2016, p. 137).

Es pertinente resaltar que esta teoría califica como un tipo de naturalismo moral, que pretende reconocer hechos morales; por ello, merece todas las críticas que el naturalismo ha recibido. Particularmente importante es el "argumento de la pregunta abierta" de Moore, según el cual frente a hechos morales es siempre pertinente seguir formulando preguntas que derivarían en una regresión infinita (Alexy, 2019 , p. 56). En el caso de la idea de una dignidad dada por Dios, podría cuestionarse por qué lo ordenado por Dios es moralmente bueno; a la respuesta podría interponérsele otra pregunta, hasta llegar al infinito.

\subsubsection{La autonomía humana}

\subsubsection{Planteamiento básico}

Este punto de vista enfatiza típicamente la capacidad de los seres vivos de distanciarse de sí mismos y tener "la posibilidad de tomar una posición sobre sus propios deseos" (Seelmann, 2019, p. 251).

Según Nussbaum, este concepto de dignidad humana ha sido reivindicado por los defensores de las teorías contractualistas, y está muy influenciado por los estoicos (especialmente por Cicerón) y los cínicos. Para ellos, las personas eran importantes y valiosas precisamente porque tenían racionalidad práctica, capacidad moral y habilidad para tomar decisiones (Nussbaum, 2019, p. 64, pp. 69-71, pp. 75-77). Esta idea es casi totalmente visible en las ideas de Kant, Locke, Smith, Hobbes, y es evidente en el enfoque de Rawls.

(14) En realidad, la falacia naturalista es una especificación de la Ley de Hume. 
Tal vez el principal exponente del planteamiento de la autonomía es Kant. Su desarrollo está concentrado en la Fundamentación de la Metafísica de las Costumbres:

Ahora bien, no es de extrañar que al recordar todos los esfuerzos que se han hecho para conocer el principio de la moral, veamos por qué han tenido que fracasar del todo. (...) [N] unca nadie se ha dado cuenta que las personas, pese a la legislación general, estaban únicamente sujetas a sus leyes personales, y que solo estaban obligadas a actuar de acuerdo a su propia voluntad legisladora, lo cual es acorde a la naturaleza. (...) Las personas no son forzadas de actuar de algún modo por la existencia de una obligación, sino por la existencia de un interés propio (...) Por lo tanto, llamaré a este principio el principio de la autonomía de la voluntad (...). (Kant, 1797, AA IV, pp. 432-433)

(...) La autonomía es entonces el fundamento de la dignidad del hombre y de cualquier ser racional. (Kant, 1797, AA IV, p. 436)

Aquí es claro que Kant identifica la dignidad en la libertad natural que tienen los seres humanos para actuar a su propia voluntad e intereses; implica una aptitud real y actual de tomar decisiones conscientes, pues, a diferencia de los animales, los humanos son conscientes de la existencia de sí mismos. Exclusivamente tales seres conscientes serían portadores de obligaciones morales (Nussbaum, 2007, p. 51, pp.159-329).

Las teorías contractualistas clásicas se desarrollan sobre la presuposición de un concepto de dignidad como autonomía y racionalidad. Asumiendo la existencia de las "Circunstancias de la Justicia" de Hume, dichas teorías consideran que la dignidad lleva a las personas a unirse y a concluir un tratado imaginario que provoca la fundación de los estados (Nussbaum, 2007, p. 29). Las capacidades y virtudes que implica la dignidad (racionalidad), junto con el autointerés -que también sería parte de una "naturaleza humana"-, causan que todas las personas se encuentren en una situación similar. Las personas serían iguales en esta medida. Pero esta igualdad también justifica el interés que tienen las personas cooperar con otros: dado que los demás son relativamente iguales a uno (ya que son racionales, aunque tengan diferentes habilidades), cada persona tiene algo que ganar del otro (Nussbaum, 2007, p. 31). Así, de acuerdo a esta teoría, la cooperación se justificaría en el beneficio mutuo que ella conlleva. Dicho beneficio mutuo no existe respecto de otros seres vivos no racionales, por lo cual no existe necesidad alguna de introducirlos o protegerlos con los contratos.

Entonces, debe tenerse presente lo siguiente sobre este planteamiento de la dignidad como autonomía: i) su fundamento es la racionalidad y la libertad; ii) en el contractualismo juega dos papeles importantes: por un lado, explica por qué la gente debería formar sociedades; por otro lado, el concepto identifica a quienes les corresponde ser partes del "contrato" y, por tanto, los derechos que otorga.

\subsubsection{Otros enfoques y críticas}

\section{a) Fundamentación de los Derechos Humanos de Robert Alexy}

Alexy ha desarrollado una fundamentación de los derechos humanos desde su teoría del discurso. Si bien esta fundamentación no se refiere directamente a la dignidad, los argumentos son pertinentes para ella dado que (i) se ocupan de justificar la titularidad de todos los derechos humanos, (ii) como se verá, se construyen sobre la autonomía y (iii) los derechos humanos suelen identificarse como derivaciones de la dignidad (Hufen, 2016, pp. 152-153).

Alexy identifica su propia fundamentación como kantiana, en la medida que (i) se basa en la idea de la autonomía e (ii) implica un principio de universalidad. La universalidad, en este caso, simplemente significa que los derechos humanos que emanan de la autonomía tienen validez para todas las personas, con independencia de su cultura (Alexy, 2016, pp. 127-129).

La fundamentación aquí se basa en algunas reglas de la teoría del discurso que ya he explicitado en la primera parte. Me refiero a las reglas de Universalidad, libertad de coerción e igualdad. Si uno está de acuerdo con la fundamentación que he referido en esa parte, está de acuerdo también con que las ideas liberales de autonomía y universalidad kantianas han sido justificadas en el plano discursivo (Alexy, 2016, p. 138). Es decir, siempre que haya una discusión con el propósito de ser racional y encontrar verdades, esas reglas deberían ser vigentes. El desafío de Alexy yace entonces en justificar esas reglas también en el plano de la acción; es decir, fuera del discurso.

Su estrategia es la siguiente. Afirma que siempre que uno tenga el interés en resolver siempre y todos los conflictos sociales a través de un consenso racional y discursivamente controlado, las reglas del discurso deberán tener vigencia en el plano real (Alexy, 2016, p. 
149); ello es así, dado que la posibilidad continua de controlar discursiva y racionalmente los consensos sociales presupone la vigencia continua de las reglas de igualdad, universalidad y libertad de coerción en el plano de la realidad, tal como si nos encontráramos en un discurso constante. En este punto, el autor afirma que esas reglas del discurso se transforman, en el plano real, en el mismo principio de la autonomía propuesto por Nino (1989, p. 230) (Alexy, 2016, p. 148): "Es deseable que la gente determine su conducta sólo por la libre adopción de los principios morales que, luego de suficiente reflexión y deliberación, juzgue validos".

Aquí se podría cuestionar qué tan factible es afirmar la vigencia universal del interés en resolver todos los conflictos sociales a través de la formación de consensos racional y discursivamente controlados. La respuesta es el mismo argumento "existencialista" que se dio al responder un cuestionamiento similar respecto de las reglas del discurso: este interés se corresponde con el interés en encontrar la "verdad", transferido al plano práctico. Siempre que la gente tenga interés en resolver conflictos de acuerdo a lo que es "verdadero", deberá necesariamente reconocer los derechos humanos; se trata de una decisión sobre realizar la potencialidad discursiva de las personas, decisión que, en la realidad, la mayoría sustantiva de todas las sociedades humanas siempre persigue (Alexy, 2016, pp. 151-153) (Alexy, 2004, p. 21).

Surge ahora la pregunta de identificar la titularidad de la dignidad propuesta aquí por Alexy. Aunque esta pregunta no es abordada de manera directa por el autor, es fácil deducir la respuesta. Serían titulares del principio de autonomía (de la dignidad) todos aquellos seres que pueden formar parte de un discurso y que, de algún modo, puedan contribuir al control racional, discursivo y constante de los consensos sociales. En este aspecto, la titularidad no dista mucho de la original kantiana: la racionalidad.

b) Crítica: la protección de humanos no racionales y animales

Nussbaum hace una importante crítica contra estos planteamientos de la titularidad de la dignidad. Si las personas son valiosas simplemente porque son racionales, entonces este concepto excluiría algunos seres vivos que, al examinarlos más de cerca, podrían merecer (y de hecho ya lo hacen en algunas sociedades) su inclusión en el concepto de dignidad, a saber, las personas discapacitadas y los animales (Nussbaum, 2007 , p. 62). Las personas con discapacidad mental reciben la misma protección que cualquier persona racional, y ello es poco discutido (Marquis, 1989, pp. 187-188). Asimismo, los animales vienen gozando de cada vez mayor protección legal en el mundo. Para decirlo con los términos de nuestra base metaética, las consecuencias de la dignidad como racionalidad no se corresponden con otros principios y convicciones de justicia sólidos. Asimismo, tampoco resisten la aplicación del principio de universalidad, pues las consecuencias de su aceptación no parecen ser discursivamente aceptables en ningún ordenamiento jurídico liberal. Parece equivocado que la racionalidad justifique la titularidad de la dignidad.

Estrictamente hablando, la dignidad como racionalidad tampoco podría justificar directamente la protección de los niños muy pequeños. Para explicar su protección, se suele utilizar una modificación ad hoc al planteamiento de la autonomía (Marquis, 1989 , p. 192). Se afirma que los bebés merecen protección porque, si bien son aun racionales, tienen la potencialidad de serlo. Es problemático contra esta defensa que los planteamientos de autonomía, de hecho, no valoran la potencialidad de la racionalidad, sino la racionalidad actual y presente. Esto es claro en Kant (Kant, 1797, AA IV, pp. 432-433) y Alexy: de sus fundamentos simplemente no se sigue la protección de una racionalidad potencial, sino actual.

\section{c) Crítica: falacia naturalista}

Marquis ofrece una versión de esta crítica. Las personas opuestas al aborto suelen alegar que la protección del embrión puede justificarse porque pertenece biológicamente a la especie humana. Frente a esto, los defensores del aborto suelen contraargumentar que sería un error inferir una norma moral a partir del fenómeno puramente biológico (la pertenencia a la especie). Este autor afirma que el concepto de autonomía merece la misma crítica, a saber, que también sería una falacia deducir una norma moral del fenómeno psicológico de poseer racionalidad (1989, p. 187).

A esta crítica ya se le ha respondido de cierto modo al exponer la justificación de las reglas del discurso, en la primera sección. Si tomamos la dignidad como ha sido fundamentada por Alexy, esta se deriva en última instancia de presupuestos irrenunciables de la comunicación humana y del concepto de verdad. Estos presupuestos son ciertamente hechos, pero a la vez tienen carácter normativo. La norma no se deduce de un hecho, sino que es un hecho en sí mismo; es un hecho y, a la vez, una norma. Aquí se podría contraargumentar que sería a la vez una falacia naturalista deducir la normatividad de una norma fáctica, y que el 
hecho de que la gente se comporte de una manera no quiere decir que debamos comportarnos de esa manera. A esta refutación se le puede responder aduciendo que la asunción de esas reglas son parte de la naturaleza humana, en la medida que los humanos vivamos en sociedad; naturalmente podría una persona elegir no seguir esas reglas discursivas jamás, pero el costo sería vivir en aislamiento de por vida. ¿Se puede realmente tener reparos frente a esta alternativa?

\section{d) Proposición rival de Marquis: el futuro valioso}

Marquis propone una teoría que pretende reemplazar el concepto de autonomía. Trata de ejemplificarla a través de un experimento mental, y pide al lector que se pregunte qué es lo que realmente está en juego en un asesinato, cuál sería su "costo". Concluye que aquello que realmente se valora en las personas (y que se pierde cuando se comete un asesinato) es un futuro valioso en el que desarrollarán sus intereses, experiencias y sentimientos (Marquis, 1989, p. 189). Además, señala que este criterio de valoración también podría incluir algunos animales, en la medida que identifiquemos qué futuro de qué animal podría ser similarmente valioso al futuro de los humanos (Marquis, 1989, p. 191).

Hay al menos dos puntos a criticar en esta teoría. En primer lugar, la explicación de Marquis presupone que no todo futuro es valioso en sí mismo (pese a que, literalmente, dice lo contrario), pues asume que el futuro de los seres humanos es valioso, y no explica por qué. Si no partiera de esta premisa, Marquis tendría que admitir que el futuro de todos los animales es valioso. En su lugar, utiliza el futuro humano como criterio de valoración del futuro de otras especies ¿Qué características definen un "futuro humano"? ¿Qué lo hace valioso? Estas preguntas abiertas nos llevan de nuevo a un concepto de dignidad que no se basa en el mero futuro. En segundo lugar, parece dudoso que el "costo" de matar se refiera principal o exclusivamente a la pérdida de un futuro. Parece más plausible una convicción de justicia con respecto a la destrucción de una subjetividad sensible, como se explicará a continuación en una posición defendida por Tooley.

e) Proposición rival: Subjetividad

Con un experimento mental, Tooley trata de demostrar que lo que valoramos en la vida de un ser vivo no es el mero fenómeno biológico, sino su subjetividad: nos pregunta si en caso le lavaran irremediablemente el cerebro a una persona, acarreando la destrucción de su personalidad, sentimientos y recuerdos, podríamos considerar que su vida continúa. La respuesta, por supuesto, es no. Aunque la vida humana como fenómeno biológico continuara, la persona sería eliminada para siempre (Tooley, 1972, p. 46). Si aceptamos esta teoría como cierta, la vida de un ser vivo estaría determinada por la existencia de un ser subjetivo -es decir, que experimenta la realidad- que tiene ciertos rasgos individuales que lo identifican y que determinan la forma en que experimenta el mundo. Si el ser vivo fuera asesinado, aquello reprochable en dicho asesinato no sería tanto la destrucción del sistema biológico que sirve de plataforma al individuo que experimenta, sino más bien la destrucción irremediable de dicho individuo. Podría teorizarse que, si fuera posible salvar la "mente" del individuo, la destrucción del cuerpo no sería calificada como asesinato (o no sería igualmente reprochable).

Partiendo de lo anterior, el propio Tooley propone una teoría de la dignidad. Sugiere que la aptitud para tener deseos es una condición necesaria para la capacidad jurídica. Sólo se pueden tener derechos si éstos se dirigen a satisfacer los deseos de un individuo. Afirma además que los deseos presuponen la capacidad de ser consciente de sí mismo y de los demás, ya que uno sólo puede desear lo que sabe y lo que puede imaginar como un objeto distinto de sí mismo (Tooley, 1972, pp. 45-47). Por lo tanto, nadie podría tener derecho a la vida si no supiera que vive y que puede morir.

La propuesta de dignidad de Tooley incurre en las mismas contradicciones de la teoría de la autonomía: excluiría a las personas con discapacidad mental, los animales y a los niños pequeños. Por ello, debemos rechazar su teoría de la dignidad; no obstante, es destacable su idea de que la dignidad de un sujeto no se calcula en función del mero fenómeno de su vida, sino de la existencia de un individuo que experimenta. Volveré más adelante a ella.

\section{f) Proposición rival de Dworkin}

Ahora analizamos la posición de Dworkin. En Life's Dominion, explica una teoría similar a la de Tooley. Según Dworkin, el derecho a la vida (y los derechos en general) presupone que un ser vivo tiene un interés en vivir (similar a los deseos de Tooley). A diferencia de Tooley, Dworkin afirma que el requisito para poder tener intereses no es la conciencia de uno mismo, sino la mera capacidad de sentir (Dworkin, 1993, p. 16). Sin embargo, Dworkin explica que la protección especial que los humanos merecen no se basa en la mera sensibilidad, sino en habilidades especiales: "poder disfrutar o no disfrutar, formar vínculos y emociones, esperar y esperar sufrir frustraciones y decepciones" (Dworkin, 1993, pp. 17-18). Sin embargo, más tarde sostiene 
que ser humano implica poseer una gran inteligencia (al menos más alta que la de los animales), y que ello también determina su protección especial (Dworkin, 1993, pp. 22-23). Por último, afirma que, aunque los animales no son titulares de derechos, los Estados podrían protegerlos por su valor intrínseco -que no precisa- (Dworkin, 1993, p. 149).

Estrictamente hablando, la teoría de Dworkin adolece de los mismos problemas que las teorías anteriores. Si bien afirma que las personas con discapacidad mental severa y los niños tendrían dignidad, Dworkin evita explícitamente la discusión filosófica sobre este tema, y afirma que, si bien los niños no son aún conscientes de sí mismos, deben contar como seres humanos sólo por razones prácticas (Dworkin, 1993, p. 23).

\subsection{3. "Teorías de la comunicación": Enfoque de las Capacidades}

Nussbaum propone una solución interesante al problema de la autonomía referido a la no-protección de humanos no racionales y animales. Adicionalmente a las críticas ya mencionadas sobre las teorías de la dignidad como autonomía, Nussbaum también critica otros dos puntos importantes:

1) Como se ha explicado, las "Circunstancias de la Justicia" del Contractualismo sugieren que las personas son principalmente egoístas, y que no pueden preocuparse tanto por los intereses de los demás como por sus propios intereses. Para Nussbaum, esta descripción de la naturaleza humana sería errónea. Las personas también son empáticas y se preocupan por el bienestar de los demás, o al menos lo hacen de un modo mayor que el descrito por ese planteamiento. Si esta crítica es cierta, entonces la premisa descriptiva del Contractualismo, de que la cooperación moral está motivada predominantemente en el interés de beneficio personal, sería inexacta. Asimismo, se abandonaría la exigencia de que sólo participen en el contrato social "personas racionales iguales", ya que el objetivo del contrato no sería la pura autoprotección, sino que también podría referirse a la protección de los demás como un fin en sí mismo (a saber, los animales y los discapacitados mentales graves) (Nussbaum, 2007, p. 62).

Esta idea es compatible con una idea que hemos revisado en la parte metaética: en el discurso moral, son las convicciones de justicia y no la interpretación de los intereses de los interlocutores aquello que, en última instancia, se discute; muchas veces se discuten cuestiones de justicia que no son directamente o predominantemente reconducibles a los participantes del discurso. Un ejemplo de ello es la discusión moral sobre la protección de sujetos que no pueden formar parte del discurso: animales y personas que no tienen racionalidad.

2) Sería erróneo y no tendría una justificación convincente limitar la dignidad a la racionalidad. La racionalidad es, de hecho, sólo una parte de la naturaleza humana. También forma parte del ser humano la experiencia de tener necesidades fisiológicas y emocionales, como la necesidad de atención. La naturaleza humana también está vinculada a la aptitud para desarrollar ciertas habilidades, como la capacidad de divertirse, de formar relaciones emocionales con otros seres (humanos y no humanos), de formar ideas y expectativas, de experimentar sentimientos, etc. A este respecto, la naturaleza animal de los seres humanos (o estas cualidades "no racionales") también es valiosa en sí misma y también forma parte de su dignidad. Ser humano implicaría darse cuenta de que los seres humanos son criaturas frágiles, con un tiempo de vida limitado, y que se esfuerzan por florecer (Nussbaum, 2007, pp. 85-90; pp. 159-160).

Asumiendo que no sólo la racionalidad de los seres humanos, sino también sus necesidades, experiencias y aspiraciones generales son valiosas en sí mismas, Nussbaum explica que los animales también merecen valoración moral, dado que experimentan -en distintos grados- vidas muy similares a las humanas, y que solo difieren de ellas por su falta de racionalidad. Pero ya se ha dicho que la racionalidad no es el único elemento que determina la valoración moral. En la medida que los animales también experimentan vidas de florecimiento, lo cual es valioso en sí mismo, ello los hace merecedores de dignidad (Nussbaum, 2019, pp. 249-250). En ese sentido, para Nussbaum, el criterio que determinaría la titularidad de la dignidad es llevar una vida de florecimiento. Aunque, en principio para Nussbaum todos los seres vivientes serían titulares de la dignidad, los derechos que la dignidad conlleva respecto de cada especie serían diferentes de acuerdo a sus capacidades (Nussbaum, 2007, p. 87, p. 347).

\subsubsection{Conclusión: ¿Quién tiene dignidad?} La doctrina de Nussbaum tiene la ventaja de superar los problemas en la concepción de la autonomía. Además, el enfoque de las 
capacidades puede explicar la valoración moral fáctica de algunas actividades (como el entretenimiento, las actividades deportivas, los vínculos emocionales con personas y animales, etc.) que pueden corresponder hoy en día a (y por lo tanto determinar la justificación de) convicciones intuitivas de justicia.

No obstante, es problemático el establecimiento de un diálogo entre las teorías constructivistas de autores como Kant, Nino, Alexy y una teoría como la de Nussbaum, que es de tradición aristotélica y, por lo tanto, metafísica. El hecho de que Nussbaum afirme varias veces en sus obras que su intención es formar una teoría que no sea metafísica (Nussbaum, 2007, p. 182) no alcanza: la autora basa el centro de su argumentación en la idea general de que las vidas de florecimiento serían valiosas, pero no explica realmente por qué. Surge la pregunta de si su propia teoría no se basaría en una falacia naturalista.

También es problemática la amplitud de esta teoría. La identificación de la dignidad en la mera capacidad de desarrollarse no excluye la dignidad de las plantas, como incluso la propia Nussbaum ha admitido (Nussbaum, 2007, p. 447). Es dudoso que tal respeto por las plantas pueda realistamente representar alguna convicción de justicia.

Propongo superar estos problemas de la siguiente manera. El argumento trascendental-pragmático de Alexy tiene la virtud de no ser metafísico y de permitir la fundamentación de la titularidad de la dignidad en la medida que ello contribuya a realizar la naturaleza discursiva del humano, que consiste en la construcción de "verdades objetivas". Lo que hace es identificar un rasgo de la naturaleza humana poco discutible, y de él derivar los criterios que determinan la racionalidad y objetividad. Alexy, como Kant, distingue entre autonomía privada y autonomía pública (Alexy, 2016, p. 127). Las reglas que protegen la autonomía pública, común a todos los humanos, se construyen utilizando un criterio de racionalidad basado en la naturaleza discursiva de las personas, que también es común a todos los humanos (las reglas del discurso). Así, las verdades públicas se construyen en el marco de criterios de racionalidad que son "públicamente" -universalmente- existentes.

Surge la pregunta por el valor y la formación de las reglas que rigen la "racionalidad" de la "verdad privada". Aquí me refiero a la moral privada: las reglas que se impone el individuo a sí mismo para guiar su vida en libertad, sin vulnerar la libertad de terceros. Si la teoría del discurso utiliza el interés por la "verdad" como criterio último para fundamentar la verdad "pública", la fundamentación de la protección de la libertad privada no puede basarse en algo distinto. El problema de la "verdad privada" es que, a diferencia de la "verdad pública", su criterio de racionalidad no puede construirse sobre características compartidas por todos, pues ese campo ya está tomado por esta última. Parecería entonces que la "verdad privada", a diferencia de la "pública" no podría utilizar un criterio de racionalidad entendido como universalidad intersubjetiva, es decir, de aceptabilidad por todos. La racionalidad de la "verdad privada" solamente podría construirse sobre factores muy particulares, profundamente distintos en cada individuo: intereses, emociones, sentimientos, etc. Sin necesidad de desviarme por esta discusión, que merece un trabajo independiente, puedo destacar lo siguiente, que es útil para mi argumento: un auténtico interés en la verdad, llevado al campo de la moral privada, justifica que se confíe al individuo la determinación de sus reglas privadas; es él quien está en mejor situación para construir "verdades" privadas, pues nadie mejor que él tiene acceso a los factores muy particulares que la construyen. En consecuencia, así como Alexy ha fundamentado la autonomía pública (y los derechos humanos) sobre un auténtico interés en la verdad, la autonomía privada también se deja fundamentar de ese modo.

De manera análoga a la fundamentación de la autonomía privada, también podría justificarse la protección de animales y personas con discapacidad mental severa en un interés en la verdad: la "verdad" práctica sería equivalente al desarrollo de vida que estos sujetos emprenderían en ausencia de condiciones limitantes.

Así como con la moral privada, respecto de estos grupos hay incluso menos criterios en común a partir de los cuales construir "verdades" en común. Falta el criterio más importante de la "verdad", que es la racionalidad. Sin embargo, no habría una razón exante para valorar negativamente el desarrollo de "verdades no-racionales" por estos grupos; la razón por la que se valora positivamente la racionalidad entre humanos, cualquiera sea su procedencia, es porque la naturaleza humana implica inevitablemente reglas que prescriben la racionalidad entre humanos; la teoría del discurso solo hace explícitas esas reglas. En el caso de entidades no racionales, una regla de ese tipo no existe. Además, sí hay elementos en común que son de hecho considerados para la construcción de nuestras verdades racionales: nuestras necesidades, capacidades, emociones, etc. En la medida que las "verdades privadas" 
no sean exclusivamente valoradas en su "verdad" por ser la expresión de una ordenación racional de intereses, sino también por ser la manifestación de emociones y necesidades "reales" (verdaderas) de un individuo, en la misma medida es valiosa también la "verdad" reflejada en la vida de animales y personas con discapacidad mental severa.

Este planteamiento no está libre de críticas. Podría refutarse, por ejemplo, que el concepto de verdad se tuerce al punto de perder su significado, ya que el concepto de verdad presupone necesariamente racionalidad. Podría responderse que su uso es correcto en la misma medida en la que "verdad" es correctamente utilizado al describir fenómenos con los que no podemos establecer un dialogo, como los fenómenos naturales. Se podría contraargumentar, también, que el interés en la verdad que justifica los derechos humanos es distinto al interés en la verdad (si es que existe alguno) que justificaría la dignidad de seres no racionales, dado que el interés del primer tipo se justifica en la participación de otros en la construcción de una verdad común, algo en lo que los seres no racionales no pueden participar.

Para responder esta crítica algo del argumento postmodernista sí podría tener utilidad: si bien es posible hablar de "verdades" racionales universalizables entre todos los humanos, esto solo es posible debido a la naturaleza racional humana, que necesariamente utiliza ideas con pretensión de universalidad en el lenguaje; fuera de la comunidad racional, nada garantiza la utilidad o superioridad de "verdades" basadas en la racionalidad. Su valor está limitado a los humanos y seres racionales y sus objetivos, y por fuera de ellos es imposible medir su valor con otras "verdades". En estas latitudes de abstracción, puedo reconocer cualificadamente una virtud del argumento postmodernista: nos pone en una situación humilde, al recordarnos que nuestra "verdad" humana-racional, prima facie y en general, no es una "verdad" superior a las "verdades" y formas de vida que reconocen otras especies para sí. Un auténtico interés en la verdad, que reconoce esta premisa, no puede evitar reconocer valor en las "verdades" que seres no racionales no pueden evitar reconocer.

También surgen preguntas críticas, como por ejemplo si la dignidad de animales merecería una misma protección que la de humanos. No obstante, mi planteamiento no puede ser fundamentado completamente aquí. Ello requeriría un trabajo independiente. El esbozo aquí propuesto deberá bastar para la argumentación que sigue.

Asumiendo que mi tesis sea acertada, propongo combinarla con una idea (ya mencionada) de Tooley. Este afirma que lo que es reprochable de un asesinato es la destrucción de una "subjetividad que puede experimentar". Este concepto engloba la mínima característica imaginable presente en sujetos con aspiraciones, emociones y necesidades: la capacidad de

\section{experimentar.}

Por lo tanto, habría que entender aquí que, según un enfoque de las capacidades modificado, todo ser vivo es titular de dignidad, ya que la protección de su subjetividad representa la expresión de una verdad; no obstante, dicha vida -el desarrollo de sus capacidades- debe poder ser experimentada por una subjetividad. El cambio que propongo tiene el efecto de hacer que esta tesis particular del enfoque de las capacidades sea más representativa de nuestras convicciones intuitivas de justicia, y a la vez pueda justificarse sobre una base racional no metafísica dada por la teoría del discurso.

¿Cuáles son las condiciones que determinan la existencia de una subjetividad que experimenta? En lo que respecta a nuestra investigación: en los humanos, al menos la existencia de un sistema nervioso activo. La aptitud para experimentar cualquier capacidad es tener un sistema nervioso funcional. No todo feto tiene un sistema nervioso funcional; sin embargo, hay un punto en que sí se desarrolla. Este es el momento más temprano en que algún grado de dignidad es argumentable.

\section{2. ¿Qué merece un titular de dignidad?} Aquí pretendo constatar algunas consecuencias normativas de la dignidad, aunque son tal vez innumerables, puesto que, según muchas opiniones, los derechos humanos y los derechos fundamentales se derivan de ella (Hufen, 2016, pp. 152-153). No me quiero extender mucho en esta sección dado que el centro de este artículo está más cercano a la identificación de la dignidad del feto; por ello, me restringiré a constatar dos categorías de normas que pueden derivarse de la dignidad, y que no son demasiado polémicas: i) la prohibición de instrumentalizar al ser humano, y ii) el derecho a condiciones mínimas que permitan una vida digna. Estas consecuencias normativas han sido construidas exclusivamente sobre presupuestos kantianos, por lo que asumen necesariamente su correspondencia con seres racionales; no puede decirse sin más que representan las consecuencias normativas de fetos con sistemas nerviosos funcionales pero aun sin racionalidad; sin embargo, ello no es muy problemático, dado que este análisis de 
la dignidad es solamente importante para analizar la dignidad de la madre.

\subsubsection{La prohibición de la instrumentalización de los seres humanos}

Esta idea se basa en el segundo imperativo categórico de Kant: "El hombre, y todo ser racional en general, existe como un fin en sí mismo, no sólo como un medio de uso arbitrario para tal o cual voluntad, sino que debe ser considerado en todo momento como un fin en todas sus acciones dirigidas tanto a sí mismo como a otros seres racionales." (Kant, 1797, AA IV, p. 428). Según Dürig, la instrumentalización se produce cuando "el hombre se degrada a un objeto, a un mero medio" (Seelmann, 2019, p. 246).

¿Cuándo se instrumentaliza a un ser humano? Nino interpreta a Kant de la siguiente manera. Kant explica literalmente: "Actúa de tal manera que trates la humanidad tanto de tu propia persona como la de todos los demás en todo momento como un fin, nunca como un mero medio". Aquí es importante reparar en el concepto de "humanidad": según Kant - como ya se ha explicado- la humanidad implica la aptitud de tomar decisiones libres y plantearse a sí mismo objetivos. Desde este punto de vista, Kant quiere decir (según Nino) que una persona es tratada como un ser humano (o no es instrumentalizada) si es tratada de acuerdo a sus objetivos y decisiones libres (Nino, 1989, pp. 250-251).

¿Cuándo se trata al hombre de acuerdo con sus objetivos y su libertad? Hay dos tipos de restricciones posibles:

(i) Los objetivos y el ejercicio de la libertad (humanidad) no deben ser restringidos por el Estado, a menos que dicha restricción sea libremente aceptada por el individuo (Nino, 1989, pp. 250-251).

(ii) Como ya se ha explicado, los Estados deben tratar y proteger por igual las diferentes libertades y planes (léase: la humanidad) de las personas, debido a que son iguales. Por consiguiente, para ello, el Estado debe limitar las libertades de algunos para preservar otras libertades (Nino, 1989, p. 212, pp. 214-215).

Por consiguiente, una persona es "utilizada" e "instrumentalizada" cuando sus objetivos y libertades son restringidos sin que la restricción sea libremente aceptada, o cuando son restringidos sin que se justifique la preservación de otras libertades.

\subsubsection{El derecho a condiciones mínimas que permitan una vida digna}

Según Nino, la dignidad también otorga un derecho a condiciones mínimas que permitan una vida digna. Esta conclusión normativa también procedería de la idea de Kant de que todo plan de vida es valioso en sí mismo (Nino, 1989, pp. 214-215); en la medida que un plan de vida no puede desarrollarse si no hay condiciones mínimas que al menos hagan posible su desarrollo, se haría preciso posibilitar dicho plan mediante la facilitación de las condiciones.

Hay muchas opiniones sobre las condiciones que necesita una vida digna para desenvolverse con dignidad. De acuerdo con nuestra conclusión sobre la dignidad humana, utilizaré el planteamiento de Nussbaum.

El enfoque de las capacidades propone que las capacidades de los seres vivos (en este caso, los humanos) son importantes, y afirma que su desarrollo debe ser posible. En este contexto, Nussbaum reconoce i) "capacidades básicas", que describen las capacidades que los humanos tienen por naturaleza; ii) "capacidades internas", que los humanos desarrollan mediante el cuidado y la educación; y iii) "capacidades combinadas", que se consideran "capacidades básicas" cuyo desarrollo y despliegue requieren condiciones externas (Nussbaum, 2019, p. 240).

Por supuesto, cualquier habilidad básica no es valiosa (como la capacidad de usar la violencia). La doctrina Nussbaum propone construir normativamente una lista de habilidades deseables (Nussbaum, 2019, p. 240). Naturalmente, no es imposible adentrarnos en este punto; para el propósito de este trabajo, debe tenerse en cuenta que las habilidades humanas incluyen lo siguiente para Nussbaum: 1) vida, 2) salud física, 3) integridad física, 4) sentidos, imaginación y pensamientos, 5) sentimientos, 6) racionalidad práctica, 7 ) relaciones sociales (“Afiliación"), 8) relaciones con otras especies, 9) entretenimiento, control sobre el propio entorno (Nussbaum, 2019, pp. 241-243).

Las consecuencias normativas de la dignidad implican que las personas no deben ser instrumentalizadas y que las personas merecen ciertas condiciones mínimas para poder desarrollar sus capacidades. Como veremos más adelante, estas dos ideas nos ayudarán a juzgar la naturaleza normativa del aborto en contra de la dignidad humana.

\section{Conflicto de dignidades: ¿El aborto vulnera la dignidad humana?}




\subsection{La dignidad del embrión}

En esta parte de la investigación describiré algunas de las posturas más importantes sobre la dignidad de los embriones y las confrontaré con las conclusiones producidas hasta aquí. Un análisis y confrontación completa de cada opinión merece un trabajo individual, por lo que los resultados de esta sección solo pueden tener valor prima facie. Retienen, no obstante, cierto valor, en la medida en que se ocupan de los planteamientos básicos de cada postura.

En primer lugar, siguiendo lo desarrollado arriba, debe tenerse presente que el momento más temprano desde el que el embrión tiene dignidad es el momento en que se puede presumir razonablemente el funcionamiento del sistema nervioso.

A continuación, analizaré algunos de los argumentos que afirman la dignidad del embrión en un momento anterior.

i) Argumentos basados en una versión de las teorías de la dote: Tales opiniones basadas en las teorías de la dote repiten sus problemas y, por lo tanto, deben ser rechazadas por las razones expuestas anteriormente.

ii) Argumento de acuerdo al cual "el derecho a la vida del embrión humano no sólo se justifica en su forma de ser, sino en el mero hecho de que viva": De acuerdo a este argumento, todas las características moralmente valiosas de la persona están igualmente presentes en todos los estadios de desarrollo humano, incluyendo la etapa embrionaria. Este argumento evita así la discusión sobre la existencia de características moralmente relevantes que determinen, independientemente, el valor moral de las personas (Birnbacher, 1995, p. 360).

El problema de estos argumentos, como señala Birnbacher, es que incurren en una falacia naturalista, pues derivan la dignidad del mero fenómeno biológico de vida humana, sin identificar los elementos moralmente relevantes (Birnbacher, 1995, p. 360). Por lo tanto, debemos rechazar este argumento.

iii) Argumento de continuidad: Según este argumento, el embrión es tan digno de protección como un ser humano adulto porque el embrión y el adulto están en una relación de continuidad: uno se convierte en el otro (Birnbacher, 1995, p. 361).

Al igual que el argumento anterior, este enfoque tiene el problema de que una idea normativa se deduce sin más del mero hecho de que el embrión se convierte en un ser humano adulto; se incurre de nuevo en una falacia naturalista, y se evita discutir qué características del ser humano determinan su apreciación.

iv) El argumento del individuo: Según este, el feto tiene dignidad porque ya está "individualizado o es un individuo" (Birnbacher, 1995, p. 362). Como Birnbacher explica correctamente aquí, es cuestionable en este argumento lo que se entiende por "individuo".

"Individuo" podría tener una naturaleza biológico-genética: Un feto se individualizaría desde el momento de la fusión nuclear, ya que el material genético que constituye un ser humano habría sido "seleccionado" desde entonces. Este problema vuelve a cometer una falacia naturalista: una norma se desprende sin más de este hecho. Además, esta "individualización genética" Ilevaría a la absurda consecuencia de que "gemelos idénticos, debido a que son genéticamente idénticos, no podrían ser identificados como individuos ni siquiera de adultos" (Birnbacher, 1995, p. 362).

"Individuo" también podría significar "que este embrión con sus características fenotípicas concretas es único e 'irremplazable', esto es innegable pero al mismo tiempo trivial. Porque en un sentido absoluto, independientemente de cualquier referencia a ciertas características, no sólo los organismos sino casi todas las cosas del mundo son únicas e 'irremplazable'” (Birnbacher, 1995, p. 362). La irremplazabilidad no constituye un criterio de valoración moral para otros fenómenos de la realidad.

v) Aplicación retroactiva de la regla de oro: La "regla de oro" afirma que otros deben ser tratados como a uno le gustaría ser tratado. En el caso del embrión, este argumento dictaría que los embriones no deben ser abortados porque a nadie le habría gustado ser abortado (Birnbacher, 1995, pp. 362-363).

Dworkin responde a este planteamiento. El argumento parte de una igualación de los intereses de los fetos a los de las personas: Los intereses de los fetos serían, en teoría, igualmente valiosos a los de las personas adultas. Según Dworkin, sería un error juzgar que el embrión puede tener intereses como un ser humano. Antes de la existencia de un sistema nervioso en funcionamiento, el embrión no puede sentir ni experimentar 
en absoluto (Dworkin, 1993, pp. 16-18).

Además, esa aplicación de la regla de oro justificaría también una regla de reproducción obligatoria, ya que -en teoría- todos desearíamos ser fecundados.

Finalmente, la regla de oro implica un principio de universalización incompleto: sí la regla moral fuera tratar a otros como a uno le gustaría ser tratado, los suicidas o las personas que simplemente no desearían haber nacido no tendrían una prohibición moral de abortar.

vi) Argumento de la potencialidad: Un embrión sería digno porque es un ser humano potencial (Birnbacher, 1995, p. 365). El problema de este argumento es que pasa por alto las distintas etapas del embrión durante las cuales las capacidades y características del feto cambian enormemente. Según Birnbacher, son precisamente estas características descriptivas cambiantes las que determinan las afirmaciones normativas sobre el valor de la protección de todo ser vivo (Birnbacher, 1995, p. 366).

Este argumento merece una respuesta similar a lo que ya hemos afirmado en contra de la opinión de Marquis: parece cuestionable que el futuro potencial de un ser vivo sea aquello que determine su dignidad. Aplicando la teoría de las capacidades modificada, parece ser que lo que se valora en la vida de un ser vivo es su carácter como subjetividad que experimenta, en la medida que sea actual.

Desde el punto de vista de la teoría de la dignidad como autonomía, este argumento tampoco es sostenible, pues -como he señalado más arriba- Kant considera valiosa la aptitud racional actual y presente, y no la mera aptitud para para adquirirla en el futuro.

vii) Argumento de prevención de la existencia: Según este argumento, todos estamos obligados a permitir la existencia futura de un ser humano, porque su existencia sería valiosa en sí misma. Desde este punto de vista el aborto sería injusto.

Este argumento merece la misma respuesta que el anterior, ya que reconoce el valor no en una subjetividad existente, sino ya en una existencia futura.

viii) Pertenencia a la especie: Una versión contundente de este argumento reconoce el valor de los embriones porque pertenecen a una especie (los seres humanos) que tiene potencialidad y capacidades valiosas (Birnbacher, 1995, pp. 368-370) (a saber: la capacidad de ser consciente de uno mismo, que reconduce al concepto de dignidad como autonomía; pero este argumento también sería compatible con el enfoque de las capacidades si se refiriera a las capacidades humanas generales).

El principal contraargumento de Birnbacher es que sería dudoso que exista una seria convicción de justicia con respecto a la mera pertenencia genérica, que reconoce la dignidad del hombre precisamente en este aspecto. El autor admite, sin embargo, que de otro modo sería un argumento de peso (Birnbacher, 1995, pp. 369-370).

La opinión de Birnbacher parece justificada después de nuestra discusión sobre la dignidad. Tanto el concepto de autonomía como el enfoque de las capacidades basan el valor de las personas y los seres vivos en su valor en sí mismo, y no en el hecho de que pertenezcan a un grupo biológico. La apreciación, como establecen las teorías, es siempre interna, y no depende de factores externos (ni mucho menos la pertenencia a un grupo).

En conclusión, ninguna de las posturas divergentes típicas parece prima facie oponerse al concepto el concepto de dignidad elaborado en este trabajo.

Nussbaum tiene una opinión en el tema. Según ella, antes de que el embrión pueda sobrevivir sin la madre, éste tiene una "dignidad potencial" (Nussbaum, 2011, p. 7). Nussbaum concluye ello, partiendo de la premisa de que no podría existir un "derecho a la dignidad" sin el correspondiente deber de respetar este derecho. Antes de que el embrión sea capaz de sobrevivir sin la madre, ella no tendría el deber de respetar la "dignidad" del embrión. Para ello, Nussbaum se basa en la teoría de Jarvis Thomson, que analiza la "dignidad" del embrión en relación con la de la madre.

\subsection{Dignidad de la madre}

Hasta aquí ya podemos anunciar algunos resultados intermedios. Si la discusión que he expresado respecto de la titularidad del feto es aceptable, el aborto no vulnera ninguna dignidad si se produce hasta antes de la existencia de un sistema nervioso funcional.

Surge aquí la pregunta sobre qué sucede cuando el feto ha cruzado esta etapa de desarrollo. Aquí ya hay un conflicto entre dignidades y cierto tipo de balance es requerido con la dignidad de la madre. Este problema tiene muchas aristas y una discusión suficiente no puede ser abarcada 
aquí. Por ello, el propósito de esta sección es destacar algunas problemáticas y proponer soluciones; algunas preguntas deberán, no obstante, quedar abiertas.

Como he explicado, la dignidad de un ser racional tiene, cuando menos, dos contenidos normativos: Que nadie debe ser instrumentalizado, y que se deben asegurar condiciones mínimas de autodesarrollo. Por lo tanto, cabe preguntarse: ¿podría la prohibición del aborto implicar una instrumentalización de la mujer? Hemos de recordar que la instrumentalización ocurre (entre otros casos) cuando se imponen restricciones o cargas a una persona sin su consentimiento.

\section{a) Restricciones y cargas del embarazo}

El embarazo tiene efectos significativos en la madre. Por un lado, puede afectar las capacidades de salud y la integridad física. Asimismo, siempre hay riesgos para la supervivencia de la mujer (Tribe, 1992, p. 103). Los efectos emocionales y sociales también pueden afectar el margen de autodeterminación de la mujer. Aunque el embarazo y el niño no sean deseados, se suele desarrollar una fuerte relación emocional entre la mujer y el niño; ello reduce la probabilidad de que el niño sea dado en adopción. "El embarazo transforma [gradualmente] a la mujer en una madre para siempre" (Tribe, 1992, p. 104). Esta situación, por supuesto, limita severamente el margen de maniobra del que dispone la mujer para formar su vida, su carrera, etc.

b) La naturaleza de la instrumentalización

En un famoso ensayo, Thomson afirma que, aunque se asumiera la dignidad del embrión, la prohibición del aborto implica necesariamente una instrumentalización de la madre. Explica su argumento mediante un experimento mental.

El lector debe imaginarse una situación en la que un violinista altamente entrenado tiene una insuficiencia renal, y para sobrevivir, debe estar conectado al sistema circulatorio de otra persona sólo durante 9 meses. En este contexto, personas cercanas al violinista secuestran y conectan a una persona al violinista durante 9 meses, para salvarle la vida. Si el secuestrado se separara del violinista, este último moriría directamente. Ahora bien, la autora nos pregunta si la persona secuestrada tendría un derecho moral a separarse del violinista (Thomson, 1971, p. 55).

La respuesta intuitiva es no. En ningún estado liberal se aceptaría que una persona sea sacrificada así en beneficio de un tercero. $Y$ este es precisamente el atractivo de la tesis de Thomson: su enfoque apela directamente a fuertes convicciones intuitivas de justicia, y lleva a muchos a creer que ni siquiera la mera supervivencia de una tercera persona podría justificar el sacrificio de la madre.

Tooley ensaya una crítica contra el enfoque de Jarvis
Thomson. Afirma que no se desprende necesariamente de la analogía que el embrión deba ser sacrificado porque el daño a la madre siempre puede ser compensado de alguna manera por el Estado (Tooley, 1972, pp. 53-54). En mi opinión, esta crítica tiene dos problemas: en primer lugar, es cuestionable que sea moralmente tolerable permitir el sacrificio de una persona de ese modo y contra su voluntad. En segundo lugar, Tooley tendría que admitir que los bienes jurídicos afectados por el embarazo no pueden ser compensados adecuadamente por dinero.

El enfoque de Thomson parece convincente. El análisis de muchas de sus críticas requeriría repetir contraargumentos parciales relativos a la dignidad a priori del embrión, y por lo general son superables apelando a las reglas del discurso (Wiland, 2000). Este no es lugar para profundizar en ellas. Me quiero detener en un problema con el argumento de Thomson, que ella misma también percibe sin ahondar en él (Thomson, 1971, pp. 57-58): ¿qué pasa si la madre acepta quedar embarazada? ¿Y qué sucede si la madre acepta el riesgo de quedar embarazada? ¿Habría todavía una instrumentalización si el Estado prohibiera el aborto?

c) Consentimiento: ¿qué sucede si la mujer acepta libremente el embarazo (o el riesgo)?

La cuestión discutida en esta parte del ensayo es crucial porque, según lo desarrollado hasta ahora, no hay instrumentalización cuando una persona acepta voluntariamente la limitación a su libertad (o, de acuerdo a sus elecciones libres, la limitación le corresponde). Entonces, si la madre aceptara quedar embarazada o asumiera el riesgo, la prohibición del aborto no implicaría una instrumentalización y habría fuertes razones para aceptarla (asumiendo además que la prohibición ocurriera solo después del momento en que es razonable contar con un sistema nervioso funcional en el feto).

Una respuesta a esta idea podría alegar que, aunque la conexión con el violinista (el embrión) fuera voluntaria al principio, 
deberíamos reconocer el derecho del donante a arrepentirse y renunciar. En respuesta a esta refutación, sostengo que ese derecho de retirada sólo podría reconocerse si el donante no supiera de antemano que su arrepentimiento causaría la muerte del violinista. Sin embargo, si el donante lo supiera antes de su consentimiento, no tendría justificación para sacrificar la vida de aquél. Esa justificación sólo se podría basar en la instrumentalización/decisión no tomada libremente, y no existiría aquí, dado que la mujer sabría desde el inicio que la muerte sería una consecuencia de su arrepentimiento. Por lo tanto, en este caso, la supervivencia del otro ser vivo tendría un mayor peso relativo, ya que ninguna instrumentalización se opondría.

¿Sería entonces plausible aceptar la prohibición del aborto siempre y cuando (i) exista un consentimiento del embarazo o de sus riesgos y (ii) el embrión pueda contar como un sujeto digno?

Esto lleva a la problemática pregunta sobre qué debe contar como consentimiento. Eso es particularmente ambiguo cuando se discute si correr el riesgo de quedar embarazada debe contar como consentimiento. No toda asunción de riesgo es considerada como consentimiento. En este respecto, hay varios criterios en la teoría de responsabilidad que normativamente suelen utilizarse para defender "aceptación ficta". Uno de los criterios más importantes es la probabilidad de que determinados actos den lugar a determinada consecuencia.

Es común que las mujeres queden embarazadas, aunque no lo deseen. Incluso el uso acumulativo de anticonceptivos no puede excluir el embarazo con un $100 \%$ de certeza ${ }^{(15)}$. En el caso de uso de anticonceptivos, podría ser tentador afirmar que no se debería considerar la existencia de algún consentimiento en tales casos, ya que el comportamiento de la mujer revelaría su voluntad de no quedar embarazada, y además reflejaría un comportamiento prudente. ¿Pero qué pasaría en otros casos?

Incluso si no se usaran anticonceptivos al tener relaciones sexuales, las posibilidades de quedar embarazada son muy bajas, con un máximo del $9 \%$ cuando se produce la ovulación ${ }^{(16)}$ (17). Siendo ello así, es altamente cuestionable imputar la responsabilidad por las consecuencias de un fenómeno muy improbable, que al mismo tiempo podría muy bien no haber sido deseado.

Comparto la opinión de Sunstein sobre este problema: determinar si se puede asignar la responsabilidad en estas circunstancias requiere el análisis de diferentes teorías de asignación de responsabilidad, lo que excede el propósito de este trabajo (Sunstein, 1992, p. 41).

En este punto un argumento consecuencialista de Sunstein es destacable: aunque se aceptara la atribución de una responsabilidad diferenciada según los anticonceptivos o las estrategias anticonceptivas utilizadas, y por lo tanto el permiso o la prohibición de abortar debiera determinarse de acuerdo a ella, sería extremadamente caro y tal vez imposible probar todos los aspectos (Sunstein, 1992, p. 42) dichos supuestos. Por lo tanto, no valdría la pena prohibir el aborto a esta escala.

\section{Conclusiones}

El principal propósito de la sección metaética era sugerir una base argumentativa que permitiese una discusión moral que (i) evitara incurrir en una regresión infinita y que (ii) no se basara en ideas metafísicas. Creo haber cumplido con estos propósitos al proponer las teorías constructivistas de Habermas y Alexy, con algunas modificaciones trasladadas de la teoría de Nino y Rawls. La fundamentación y reglas de la teoría del discurso sirven para criticar algunos argumentos durante el trabajo, como para servir de base a la fundamentación de un concepto propio de la dignidad.

Al analizar los planteamientos de la dignidad humana, en la segunda sección he expuesto el planteamiento básico kantiano de la dignidad como autonomía y una fundamentación reciente por Alexy inspirada en Nino. He confrontado este planteamiento a algunas críticas. La más importante proviene de Nussbaum, cuyo planteamiento pretende resolver con la teoría de las capacidades. La teoría de las capacidades es, no obstante, de índole metafísica. He sugerido una solución a

(15) Véase Planned Parenthood. If you use both a condom and birth control, are you $100 \%$ protected from getting pregnant? https://www. plannedparenthood.org/learn/teens/ask-experts/if-you-use-both-a-condom-and-birth-control-are-you-100-protected-from-gettingpregnant

(16) Véase The Emergency Contraception Website. What is my risk of getting pregnant if I have sex without using contraception or my birth control fails?' https://ec.princeton.edu/questions/risk.html

(17) Véase American Pregnancy Asociation. 'Can You Get Pregnant With Precum?' https://americanpregnancy.org/getting-pregnant/ can-you- get-pregnant-with-precum/ 
los problemas de ambas teorías, al proponer un criterio de dignidad que también puede basarse en el argumento trascendental pragmático de la teoría del discurso, llevando a consecuencias normativas similares a las propuestas por la teoría de las capacidades. No obstante, esa solución sugerida está solo planteada, y una fundamentación completa requiere de un trabajo independiente.

Según el concepto de dignidad que he propuesto, el embrión sólo tendría cierto grado de dignidad humana si se puede demostrar en él un sistema nervioso que funcione. Sólo a partir de este momento se podría considerar la posibilidad de prohibir el aborto. Este resultado, no obstante, solo tiene valor prima facie, pues un análisis más profundo de cada una de las posturas divergentes típicas sobre la dignidad del feto es requerido.

Si no queremos vulnerar la dignidad de la madre, la prohibición del aborto tendría que limitarse a los casos en que (i) el feto tenga un sistema nervioso funcional y (ii) la madre haya elegido libremente quedar embarazada. De lo contrario, sería instrumentalizada.

Es problemático vincular el concepto de "libre decisión" o "consentimiento" con las normas de asignación de responsabilidades. Esto es particularmente problemático si la madre, aunque no quería el embarazo, fue "negligente". Estos problemas deben ser examinados con más detalle en investigaciones posteriores.

\section{Referencias bibliográficas}

Alexy, R. (2004). Menschenrechte ohne Metaphysik?. Deutsche Zeitschrift für Philosophi, 52(1), 15-24. https://doi.org/10.1524/dzph.2004.52.1.15

Alexy, R. (2016). Diskurstheorie und Menschenrechte. En Recht, Vernunft, Diskurs: Studien zur Rechtphilosophie (pp. 127-164). Suhrkamp.

Alexy, R. (2019). Theorie der juristischen Argumentation.Suhrkamp Verlag.

Austin, J. L. (1962). How to do things with Words (1. ${ }^{\text {a }}$ ed.). Harvard University Press.

Birnbacher, D. (1995). Gibt es rationale Argumente für ein Abtreibungsverbot?. Revue Internationale de Philosophie, 49(193), 357-373. https://www.jstor. org/stable/23954801?seq=1

Chalmers, A. (2013). What is this thing called science? (4. ${ }^{\text {a }}$ ed.). University of Queensland Press.
Dixon, R. \& Nussbaum, M. (2011). Abortion, Dignity and Capabilities Approach. University of Chicago Public Law \& Legal Theory Working Paper, (345), 1-19. https://doi.org/10.1017/CBO9780511980442.006

Dworkin, R. (1993). Life's Dominion: An Argument About Abortion, Euthanasia, and Individual Freedom (1. ${ }^{\text {a }}$ ed.). Alfred A. Knopf.

Freundlieb, D. (1975). Zur Problematik einer Diskurstheorie der Wahrheit. Zeitschrift für allgemeine Wissenschaftstheorie, 6(1), 82-107. https://www.jstor.org/stable/25170345?seq=1

Habermas, J. (1973). Wahrheitstheorien. En H. Fahrenbach \& W. Schulz, Wirklichkeit und Reflexion: Walter Schulz zum 60. Geburtstag (pp. 253-266). Neske.

Habermas, J. (1982). Theorie des kommunikativen Handelns. Frankfurt am Main: Suhrkamp Verlag.

Habermas, J. (1998). Richtigkeit vs. Wahrheit. Deutsche Zeitschrift für Philosophie, 46(2), 179-208. https://doi.org/10.1524/dzph.1998.46.2.179

Hare, R. (1963). Freedom and Reason. Oxford University Press.

Hart, H. (1963). Law, Liberty and Morality (1. ${ }^{\mathrm{a}}$ ed.). Oxford University Press.

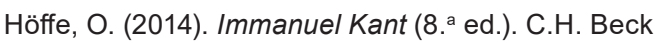

Hufen, F. (2016). Staatsrecht II, Grundrechte. C.H. Beck.

Hume, D. (1740). Traktat über die Menschliche Natur.

Kant, I. (1797). Grundlegung zur Metaphysik der Sitten.

Keuth, H. (1979). Erkenntnis oder Entscheidung? Die Konsenstheorien der Wahrheit und der Richtigkeit von Jürgen Habermas. Zeitschrift für allgemeine Wissenschaftstheorie, 10(2), 375-393). https://www.jstor. org/stable/25170520?seq=1

Marquis, D. (1989). Why Abortion is Inmoral. The Journal of Philosophy, 86(4), 183-202. https://doi.org/10.2307/2026961

Nino, C. (1989). Ética y Derechos Humanos. Editorial Astrea.

Nussbaum, M. (2007). Frontiers of Justice: Disability, Nationality, Species Membership (The Tanner Lectures on Human Values). Harvard University Press.

Nussbaum, M. (2019). The Cosmopolitan Tradition: A Noble but Flawed Ideal. Belknap Press: An Imprint of Harvard University Press.

Popper, K. (1973). Logik der Forschung. Mohr Siebeck Verlag.

Rawls, J. (1971). A Theory of Justice. Harvard University Press. https:// doi.org/10.2307/j.ctvjf9z6v

Seelmann, K. (2019). Rechtsphilosophie. C.H. Beck.

Sunstein, C. (1992). Neutrality in Constitutional Law (with Special Reference to Pornography, Abortion, and Surrogacy). Columbia Law Review, 92(1), 1-52. https://chicagounbound.uchicago.edu/cgi/ viewcontent.cgi?article=12371\&context=journal_articles

Thomson, J. (1971). A Defense of Abortion. Philosophy \& Public Affairs, 1(1), 47-66. https://www.jstor.org/stable/2265091

Tooley, M. (1972). Abortion and Infanticide. Philosophy \& Public Affairs, 2(1), 37-65. https://www.jstor.org/stable/2264919

Tribe, L. (1992). Abortion, The Clash of Absolutes. W.W. Norton \& Company. https://doi.org/10.1215/03616878-17-1-177

Wiland, E. (2001). Unconscious violinists and the use of analogies in moral argument. Journal of Medical Ethics, 26(6), 466-468. http://doi. org/10.1136/jme.26.6.466 